\title{
Efficacy of Light-Activated Sealant on Enamel Demineralization in Ortho- dontic Patients: An Atomic Force Microscope Evaluation
}

\author{
Suzi F. Shinaishin ${ }^{\mathrm{a}}$, Safaa A. Ghobashy ${ }^{\mathrm{b}}$ and Tarek H. EL-Bialy ${ }^{\mathrm{b}, \mathrm{c}_{*},}$ \\ ${ }^{a}$ College of Dentistry, Ain Shams University, Cairo, Egypt \\ ${ }^{b}$ College of Dentistry, Tanta University, Tanta, Egypt \\ ${ }^{c}$ Faculty of Medicine and Dentistry, University of Alberta, Edmonton, Canada
}

\begin{abstract}
Objective: The purpose of this study was to investigate the efficacy of (Pro Seal) sealant in preventing enamel decalcification in-vivo and compare its effect with fluoride varnish and unfilled sealant using atomic force microscopy.

Materials and Methods: Eight orthodontic patients who were candidates for extraction of all first premolars for orthodontic treatment were recruited to this study. Thirty two premolars (upper and lower) were randomly divided into four groups $(\mathrm{n}=8)$ for each group, 4 maxillary and 4 mandibular); Control (no -treatment); Fluoride varnish, Unfilled sealant (Light Bond) and filled sealant (Pro-Seal). After two months the brackets were debonded and the teeth were extracted and prepared for Atomic force microscopic scanning. Each sample was scanned twice at two different scan areas 50 and $10 \mu \mathrm{m}$ at the buccal cervical third of the crown. Images were recorded with slow scan rate and resolution and the mean roughness height and total surface area were calculated for each scan area. Comparison between groups was performed using one way analysis of variance test with level of significance was set to be 0.05 .
\end{abstract}

Results: Pro Seal treated samples show the lowest roughness height and total surface area.

Conclusion: Pro Seal was the most effective prophylaxis technique in preventing enamel demineralization during orthodontic treatment.

Keywords: Orthodontic bonding, atomic force microscopy, enamel surface roughness.

\section{INTRODUCTION}

Enamel demineralization is an undesirable outcome of orthodontic fixed appliance therapy, especially in patients with poor oral hygiene. This lesion can jeopardize the esthetic benefits of orthodontic therapy [1]. Placing of fixed orthodontic appliance alters the oral environment, causing both quantitative and qualitative changes in dental plaque [2]. Enamel demineralization adjacent to bonded orthodontic brackets might be partly due to the rough, retentive and decalcified surface of enamel produced by acid etching and lack of sealant [3]. Demineralization has been reported as much as $50 \%$ of teeth treated with brackets and in up to $50 \%$ of orthodontic patients [4-6].

To optimize results of orthodontic treatment, decalcification prophylaxis is particularly important during active orthodontic mechanotherapy [7]. Many proposed strategies are similar to measures of general caries prevention, such as patient motivation, nutritional counseling, plaque staining, professional tooth cleaning [8], chlorhexidine use [9] and fluoridation $[10,11]$. Enamel demineralization has been demonstrated in vivo around orthodontic brackets after only

*Address correspondence to this author at the 4051C Dentistry/Pharmacy Centre University of Alberta, Edmonton, Canada T6G 2N8;

Tel: + 780-492-2751; Fax: + 780-492-1624; E-mail: telbialy@ualberta.ca
1 month [11]. It is widely accepted that fluoride exerts its anticariogenic properties by the formation of fluoroapatite in the outer enamel surface that has low solubility in acid environment [12]. Reports suggest that topical fluoride applications in the form of toothpastes, $[11,13]$ gels, $[14]$ rinses, $[5$, $11,13,15]$ and fluoride varnishes [16] might reduce or eliminate decalcification during fixed orthodontic treatment. However, the effectiveness of these products is directly related to the patient's compliance, resulting in only limited benefit $[14,17]$.

New materials have been introduced to orthodontists that protect the susceptible area adjacent to bonded orthodontic attachment, and require no patient compliance. One approach is to use glass ionomer cement for band cementation and bonding orthodontic brackets [18, 19]. Another promising material is fluoride releasing resin [20, 22]. However, there is a need for improvement in both glass ionomers and fluoride releasing resins before these products will gain wide acceptance in orthodontic bonding [23-26].

Application of resin sealant on the enamel surface around and beneath the orthodontic bracket was thought to provide several benefits such as increased bond strength, sealing of etched enamel, and protection against demineralization around orthodontic brackets $[27,28]$. The chemically cured sealants do not effectively seal smooth enamel surface, because of oxygen inhibition of polymerization [29-31]. On the 
other hand, light-cured sealants have been proven to cure completely on smooth enamel surfaces and prevent enamel demineralization effectively in-vitro [31, 32]. However, invivo studies demonstrated that the light-cured unfilled resin could not provide more protection than the chemically cured sealant, as wearing off or breaks in the sealant layer might result in decalcification [33].

Pro Seal, a new highly filled light-cured resin, can be considered for use as a preventive method to reduce enamel demineralization adjacent to orthodontic attachments, particularly in patients who exhibit poor compliance with oral hygiene and home fluoride use. It was claimed, by the manufacturer, to protect enamel surface and withstand mechanical (tooth brushing) and chemical (acid attack) wearing [3]. Pro Seal was not supposed to have a negative influence on shearpeel bond strength in vitro. Previous evaluation showed no significant change in shear-peel bond strength either when Pro Seal was used in addition, or when that fluoridereleasing, light-curing sealant was substituted for the bonding agent $[34,35]$.

The initial stage in enamel dissolution involves demineralization of the outer few micrometers of tissue due to penetration of acids, leading to loss of calcium and phosphate, which results in softening of the structure [36]. Atomic Force Microscopy (AFM) is considered an ideal method for biological imaging, since specimens do not need to be dehydrated, fixed stained or coated [37]. Moreover, it has an advantage over other ultra high vacuum measuring equipments as the specimen is imaged in its hydrated state in open air condition at room temperature. Thus enamel is not subjected to dehydration and high pressure difference that could affect topographical features. The principle of surface area calculation by AFM depends on the acquisition of 3-D topographical surface data taking in consideration the variation in surface height in Z- direction [38].

Therefore, the purpose of this study was to investigate the efficacy of Pro seal in preventing decalcification in vivo using AFM and compare its effect with fluoride varnish and unfilled sealant.

\section{MATERIALS AND METHODS}

Eight female patients (13-15 years) from the postgraduate orthodontic clinic at Tanta University with class I Angle malocclusion were recruited for the present study. All patients received full bonded straight wire system (American Orthodontics, USA). All patients and parents consented to participate in this study and all work was in compliance with ethics regulation at Tanta University. All patients required extraction of their four first premolars for orthodontic treatment with fixed appliance. The premolars were free from cracks, caries or filling and have a sufficient clinical crown length to allow bracket placement at the standardized position. The patients were provided with oral hygiene instructions.

In each patient, the four first premolars were randomly assigned to one of the following treatment groups: control (No treatment); fluoride varnish; filled sealant and unfilled sealant. This distribution allows the same environment for all the tested teeth, so we had four subgroups each contained 8 premolars (4 maxillary and 4 mandibular), study design illustrated in Fig. (1).

The enamel surfaces of all teeth were polished with pumice for 10 seconds, rinsed with water and dried with compressed oil-free stream, and the different materials were applied as follow:

\section{Control (Untreated Group)}

The enamel surface was etched for 30 seconds with $37 \%$ phosphoric acid gel at $4 \mathrm{~mm}$ gingival from the buccal cusp tip and centered along the long axis of the tooth, rinsed with water for 30 seconds, and air dried thoroughly. The standard edgewise brackets were bonded with chemically cured unfilled resin (Rely -a- Bond, No mix technique (Reliance Orthodontic products-Inc. Itasca, IL, USA) according to the manufacturer instruction.

\section{Fluoride Varnish Group}

After bracket bonding (the same steps as in the nontreated group), the teeth were air dried and fluoride varnish (Duraflor, 3M, Unitek, Monrovia, CA, USA) was applied in a thin layer with a bonding brush on the buccal surfaces surrounding the brackets and allowed to dry for 5 minutes. The patients were instructed to refrain from tooth brushing until the next morning after the application.

\section{Unfilled Sealant Group}

The whole buccal surface was etched for 30 seconds with $37 \%$ phosphoric acid gel, rinsed with water for 30 seconds and air dried, the brackets were bonded. An unfilled, lightcured sealant (Light Bond Sealant, Reliance, Orthodontic Products, Itasca, IL, USA) was applied in a thin, uniform layer on the etched enamel around the brackets with a brush and then light cured with a curing light (Cromalux E, $330 \mathrm{v}$ $50 / 60 \mathrm{hz}$, Germany) for 20 seconds.

\section{Filled Sealant Group}

After etching and bracket bonding, (the same as in the unfilled group), a filled light-cured sealant (Pro-seal) was applied in a thin uniform layer on the etched enamel with brush around the brackets, and then light cured with the curing light for 20 seconds.

After 2 months, the brackets were debonded and the premolars were extracted. Debonding protocol included a non-traumatic technique to the enamel of the involved teeth using Debracketing Instrument (3M Uniteck, Monrovia, California, USA). This was performed to ensure that no possible enamel micro-fracture around the bracket bases may occur. All premolars were coded by an independent investigator. Codes were decoded after final AFM analysis and only at the time of statistical analysis. The roots and lingual parts of the crowns were cut off with a diamond disk on lowspeed without contamination on the buccal surfaces, rinsed with distilled water and stored in non-ionized water at $4 \mathrm{C}^{\circ}$.

The samples were rinsed ultrasonically in non-ionized water for 10 minutes excess water was removed gently with absorbing paper. Each specimen was mounted on the microscope stub to be imaged at room temperature in an open air condition in its hydrated state. 


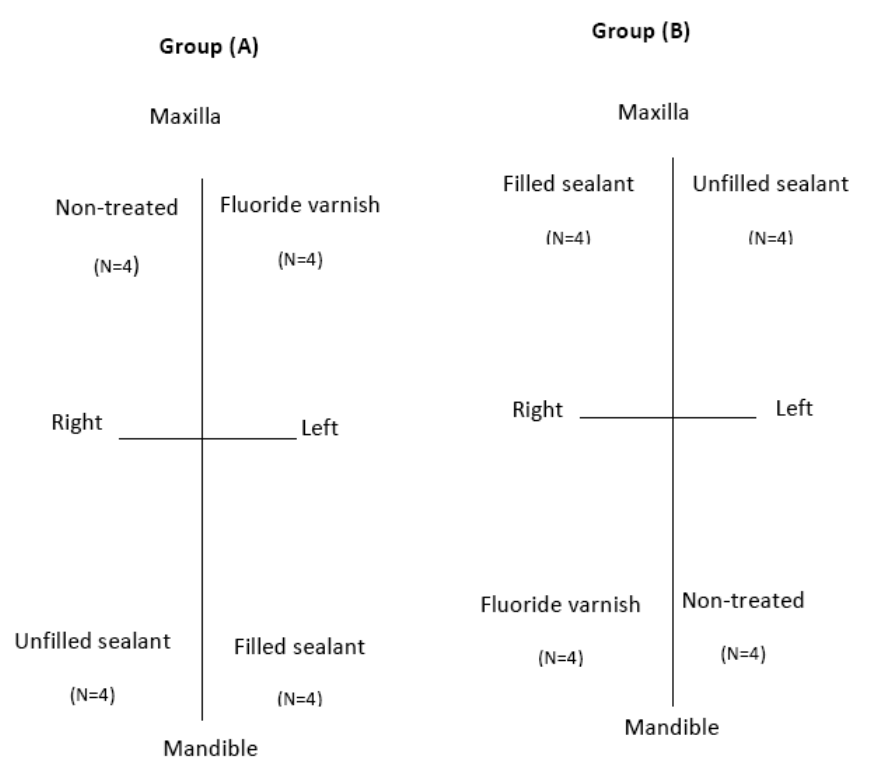

Fig. (1) Study design.

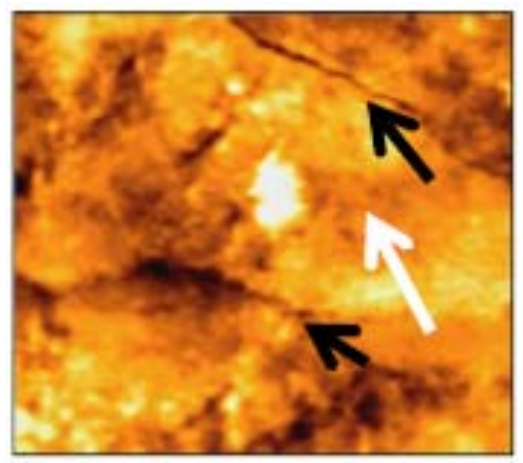

Fig. (2). Narrow grooves (black arrows) and flattened perikymata ridges (white arrows) with cracks and many destructed areas of non-treated enamel surface $(50 \times 50 \mu \mathrm{m})$.

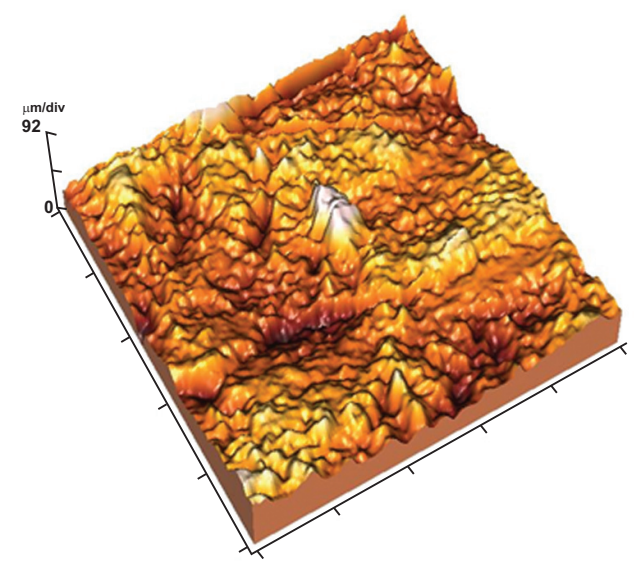

Fig. (3). 3-D image showing high surface irregularity with localized deep areas.

Tapping mode measurements were performed with an Atomic force microscope (AFM) (Auto probe CP-researcher, Thermo-microscope, Sunnyvale, CA, USA) in the National Institute for Standards (NIS), Cairo, Egypt. Each sample was scanned at two different scan areas $(50 \mu \mathrm{m}$ and $10 \mu \mathrm{m})$ at the cervical third of the crown. We used the cervical third of the

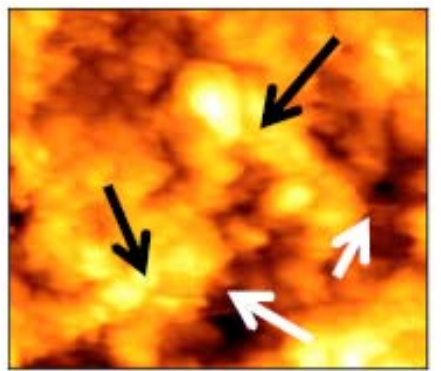

Fig. (4). Tightly packed crystals (black arrows) with focal destruction areas (white arrows) $(10 \times 10 \mu \mathrm{m})$.

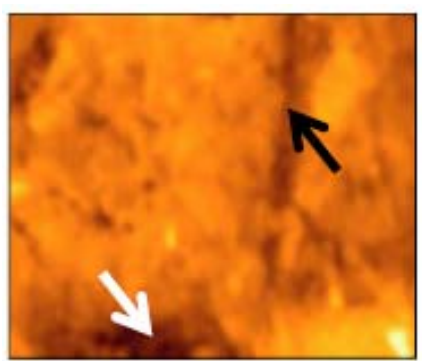

Fig. (5). Moderately wide perikymata groove (black arrow) and localized areas of destruction (white arrows) of varnish group (50x50 $\mu \mathrm{m})$.

crown (around the bracket base) which is the area less likely to be cleaned by patients. Images were recorded with slow scan rate and resolution of $512 \times 512$ pixels per image. The collected 3-D topographical data were analyzed using data analysis soft ware (SPM lab NT ver.5.01). The mean roughness height $(\mathrm{RH})$ and the total surface area (SA) were measured for each scanned area, and numerical data were presented as means and standard deviations.

Statistical Analysis: Difference between groups was performed using one way analysis of variance and Post Hoc LSD test was used to analyze the data. Level of significance $(\alpha)$ was set at 0.05 .

\section{RESULTS}

\section{Surface Topography}

Examination of AFM images and the numerical data revealed no significant difference between the samples within the same group with reference to location (maxillary and mandibular).

\section{Non-Treated Group}

AFM tapping mode images of $50 \times 50 \mu \mathrm{m}$ scanned area revealed that the enamel surface presented narrow grooves and flattened perikymata ridges with cracks and destructed areas in the surface (Fig. 2). The 3-D image showed high surface irregularity and focal deep areas corresponding to the cracks seen in the 2-D image (Fig. 3). The enamel surface presented an obvious defective crystal arrangement with wide inter-crystalline spaces (Fig. 4).

\section{Fluoride Varnish Group}

The enamel surface presented wide perikymata grooves, non obvious perikymata ridges (Fig. 5) and highly rough 


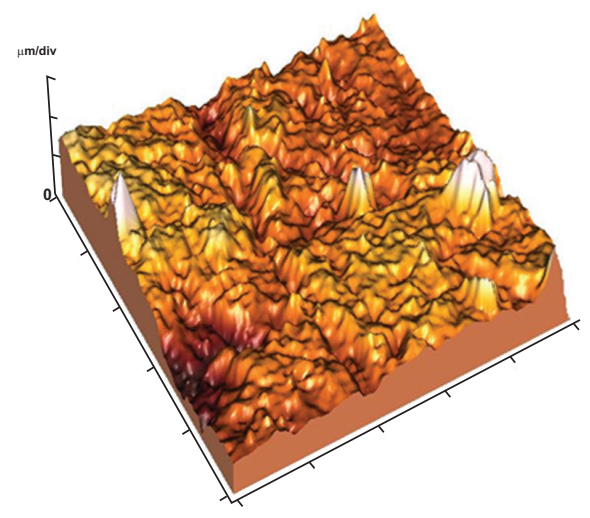

Fig. (6). 3-D image showing highly rough enamel surface with wide perikymata grooves.

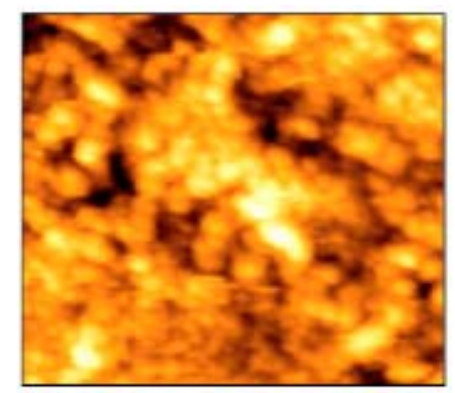

Fig. (7). Defective crystal arrangement of varnish treated enamel surface $(10 \times 10 \mu \mathrm{m})$.

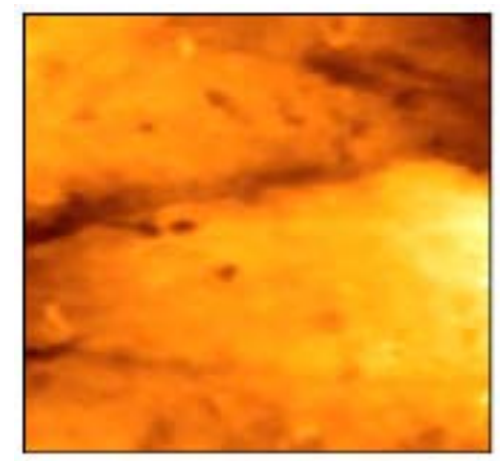

Fig. (8). AFM image of unfilled sealant group presented wide perikymata grooves and flattened perikymata ridges $(50 \times 50 \mu \mathrm{m})$.

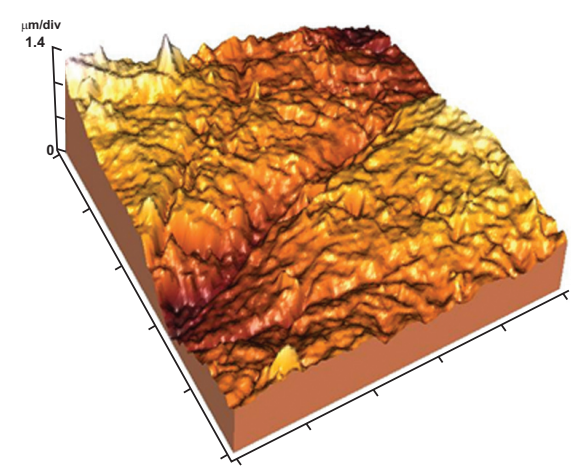

Fig. (9). 3-D image showing moderately rough enamel surface and wide perikymata groove.

enamel surface in the 3-D image (Fig. 6). The images of $10 \times 10 \mu \mathrm{m}$ scan area revealed tightly packed crystals with

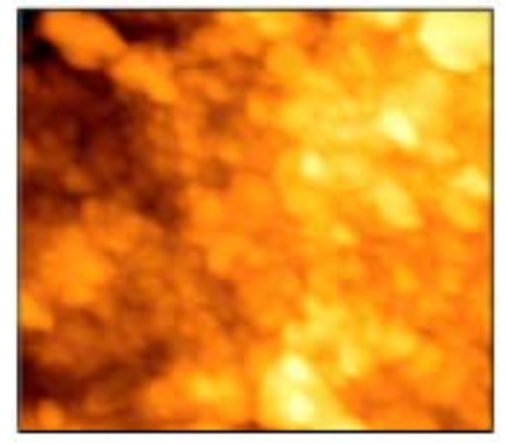

Fig. (10). AFM image showing tightly packed enamel crystals. $(10 \times 10 \mu \mathrm{m})$.

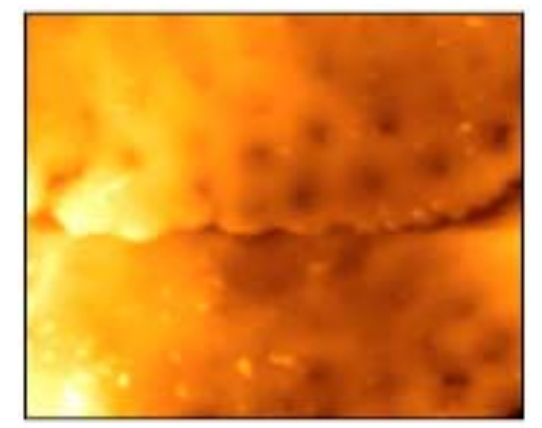

Fig. (11). AFM image of pro seal treated enamel showing perikymata ridge and groove with obvious focal holes $(50 \times 50 \mu \mathrm{m})$.

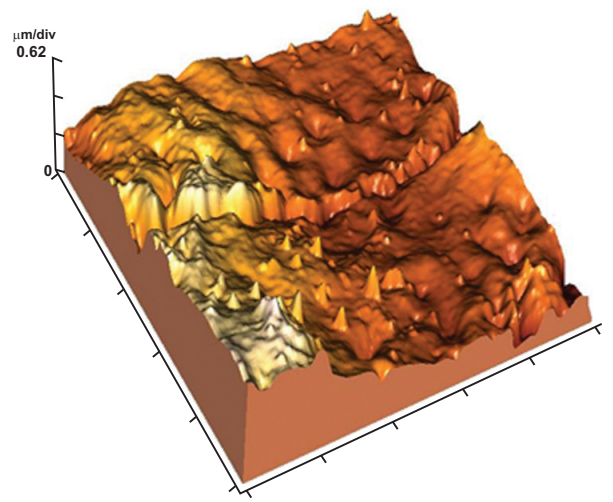

Fig. (12). 3-D image of (Fig. 2) showing relatively smooth enamel surface between the focal holes.

focal destruction areas (Fig. 7).

\section{Unfilled Sealant Group}

The enamel surface showed moderately wide but shallow perikymata grooves and localized areas of destruction in the enamel surface (Fig. 8). The surface appeared with moderate roughness in the 3-D image (Fig. 9). Tightly packed enamel crystals with no evidence of focal holes was detected in 10x10 $\mu \mathrm{m}$ image (Fig. 10).

\section{Filled Sealant (Pro Seal) Group}

The enamel surface showed perikymata grooves as wavelike parallel rings and obvious perikymata ridges. The enamel surface exhibited localized depressions (focal holes) with no evidence of rod ends (Fig. 11). The 3-D image revealed relatively smooth enamel surface (Fig. 12). Images of 


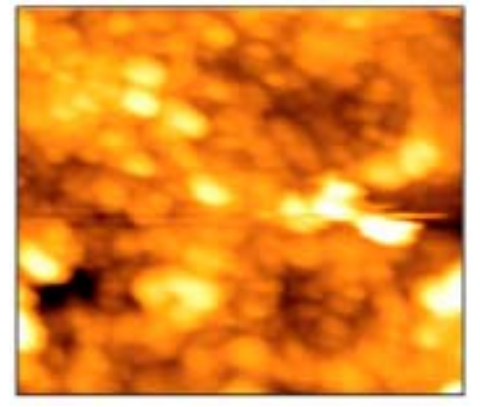

Fig. (13). AFM image showing tightly arranged crystals around conical depressions $(10 \times 10 \mu \mathrm{m})$.

\section{Roughness height (RH )}

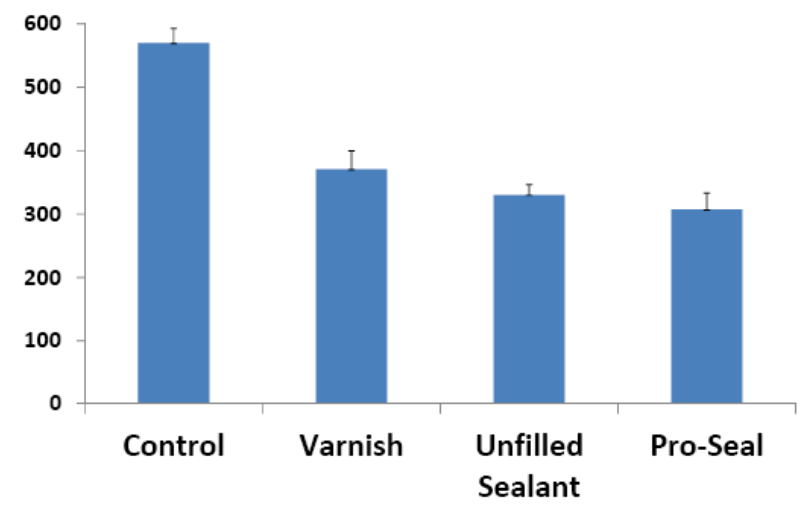

Fig. (14). Histogram showing the mean roughness height in the different groups.

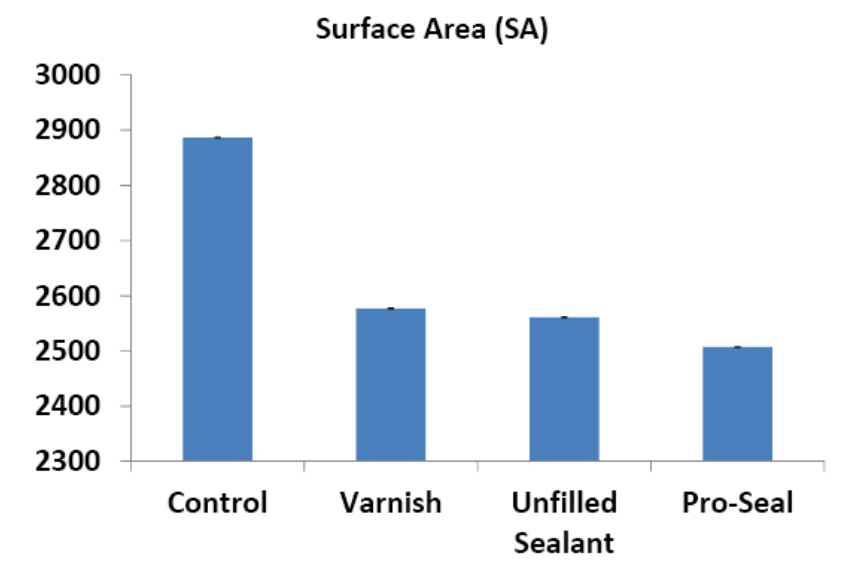

Fig. (15). Histogram showing the mean surface area in the different groups.

$10 \mathrm{x} 10 \mu \mathrm{m}$ revealed the presence of conical depression (focal holes) surrounded by tightly arranged crystals (Fig. 13).

\section{Statistical Analysis}

The means and standard deviations of the roughness height (RH) and total surface area (SA) of the scanned areas were represented in Table $\mathbf{1}$ and Figs. $(\mathbf{1 4}, \mathbf{1 5})$. One way ANOVA test revealed that RH and SA in the untreated group were significantly higher than other groups while the Pro Seal group showed the smallest values mean. There were significant differences $(p<0.001)$ between three treatment groups and the untreated group concerning RH \& SA (Tables 2-5).
Table 1. Mean and SD. of Roughness Height and Total Surface Area in all Groups

\begin{tabular}{|c|c|c|}
\hline & Ra & SA \\
\hline control & $569.7 \pm 2.3$ & $2886.6 \pm 9.20$ \\
\hline varnish & $370.54 \pm 2.19$ & $2577.2 \pm 5.3$ \\
\hline u.sealant & $330.28 \pm 1.62$ & $2561.2 \pm 8.07$ \\
\hline $\begin{array}{c}\text { pro seal } \\
\text { varnish }\end{array}$ & $307.24 \pm 2.58$ & $2507.2 \pm 7.08$ \\
\hline
\end{tabular}

\section{DISCUSSION}

Since orthodontic bonding technique involves initial enamel etching to provide micromechanical irregularities to enhance bonding, it is important to understand potential decalcification around orthodontic brackets with or without using prophylactic materials. AFM was used in the current study for characterization of surface structures of enamel because it is very sensitive to the initial phases of enamel dissolution even when the dissolution occurs at very low rate. The characterization of surface structures by tapping mode images of the present study revealed that Pro Seal treated enamel samples are typical to that of normal human enamel. The focal holes that were seen at the enamel surface would be due to loss of enamel caps as a result of physiological wear of enamel surface due to function as described by Barkovitz et al. [39].

Our experiment showed that Pro Seal group had the least values of RH \& SA among all the groups. This may suggest that adding filler particles into the sealant may improve and increase the thin layer being retained throughout treatment, and offer adequate resistance against wear in vivo. The smooth enamel surface with intact surface details, (perikymata ridges and focal holes), denoted that Pro Seal could have provided protection to the enamel from acid penetration and preserve crystal organization, which is in agreement with that described by Farimo et al. [40], and Schaad et al. [41], in normal condition. Also the shape of the crystal was typical to that described by Kikham et al. [42]. They reported that enamel proteins appeared to adopt the form of spheres approximately 30 to $50 \mu \mathrm{m}$. in diameter closely resemble previously reported nanosphere structure in vitro [43] and in vivo [44]. The obtained results are in agreement with $\mathrm{Hu}$ et al. [3]. They evaluated the third molar teeth quantitatively by cross sectional micro hardness testing and reported that, Pro Seal offers adequate resistance against wear during tooth brushing and essentially complete protection against decalcification in vitro. Also Chain et al. [45], found that Pro Seal exhibited statistically significant reduction in carious lesion initiation and progression in vitro.

The unfilled sealant group showed more protection to the enamel surface than varnish and control groups, as indicated from the mean values of RH and SA. The moderately wide and shallow perikymata grooves with moderate surface roughness were presented in 2D and 3-D images, denoted that there was a loss of the outer few micrometers of enamel surface due to softening of enamel, resulting in localized areas of destruction which was less than that observed in varnish and control groups. This result was different from that obtained by some previous studies [3, 46, 47] which 
Table 2. 1-Way ANOVA of Roughness Average (Ra) Variance Between and within the Tested Groups: Ra ( $\mu \mathrm{m})$

\begin{tabular}{|c|c|c|c|c|c|}
\hline & Sum of Squares & df & Mean Square & P & Falue \\
\hline \hline Between Groups & 215073.169 & 3 & 71691.056 & 14862.100 & .000 \\
\hline Within Groups & 77.180 & 16 & 4.824 & & \\
\hline Total & $\mathbf{1 5 1 5 0 . 3 4 9}$ & $\mathbf{1 9}$ & & & \\
\hline
\end{tabular}

Table 3. Multiple Comparisons Using Post Hoc LSD Test: Dependent Variable: Ra $(\mu \mathrm{m})$

\begin{tabular}{|c|c|c|c|}
\hline (I) Group & (J) Group & Mean Difference (I-J) & P-Value \\
\hline \hline Control & u. sealant & $239.4400^{*}$ & .000 \\
\hline & Pro seal & $262.4800^{*}$ & .000 \\
\hline & Varnish & $199.1800^{*}$ & .000 \\
\hline u. sealant & Control & $-239.4400^{*}$ & .000 \\
\hline & Pro seal & $23.0400^{*}$ & .000 \\
\hline Pro seal & Varnish & $-40.2600^{*}$ & .000 \\
\hline & Control & $-262.4800^{*}$ & .000 \\
\hline & u. sealant & $-239.4400^{*}$ & .000 \\
\hline Varnish & Varnish & $-63.3000^{*}$ & .000 \\
\hline & Control & $-199.1800^{*}$ & .000 \\
\hline
\end{tabular}

Table 4. 1-Wat Anovaanalysis of (SA) Variance Between and within the Tested Groups: Sa $\left(\mu \mathrm{m}^{2}\right)$

\begin{tabular}{|c|c|c|c|c|c|}
\hline & Sum of Squares & df & Mean Square & P-Value \\
\hline \hline Between Groups & 442037.350 & 3 & 147345.783 & 2586.148 & .000 \\
\hline Within Groups & 911.600 & 16 & 56.975 & & \\
\hline Total & $\mathbf{4 4 2 9 4 8 . 9 5 0}$ & $\mathbf{1 9}$ & & & \\
\hline
\end{tabular}

Table 5. Multiple Comparisons Using Post Hoc LSD Test: Dependent Variable: SA ( $\left.\boldsymbol{\mu m}^{2}\right)$

\begin{tabular}{|c|c|c|c|}
\hline (I) Group & (J) Group & Mean Difference (I-J) & P-Value \\
\hline \hline Control & u. sealant & $309.4000^{*}$ & .000 \\
\hline & Pro seal & $379.4000^{*}$ & .000 \\
\hline & Varnish & $325.4000^{*}$ & .000 \\
\hline u. sealant & Control & $-309.4000^{*}$ & .000 \\
\hline & Pro seal & $70.0000^{*}$ & .000 \\
\hline Pro seal & Varnish & $16.0000^{*}$ & .004 \\
\hline & Control & $379.4000^{*}$ & .000 \\
\hline Varnish & u. sealant & $-70.0000^{*}$ & .000 \\
\hline & Varnish & $-54.0000^{*}$ & .000 \\
\hline & Control & $-325.4000^{*}$ & .000 \\
\hline
\end{tabular}

The mean difference is significant at the 0.05 level.

demonstrated that the demineralization lesion formed in unfilled sealant group was not different from the lesions in the control groups, due to etched enamel underneath the sealant being exposed to the acid attack.
On the other hand, the results of the present study are in accordance with the findings of Ceen and Gwinnelt [48], Joseph et al. [49], Frazior et al. [50]. They reported that the protection afforded to the enamel did not just relay on reten- 
tion of the superficial unfilled resin coverage. The enamel surface proved to be resistant to carious attack as long as the resin tags were present, which have been shown to extend from 80 to $170 \mu \mathrm{m}$ into the enamel surface, even after mechanical removal of the sealant.

The present study revealed that the varnish group presented a more destructed enamel surface. Widening and deepening of the perikymata grooves together with cracks that were detected in the enamel surface could be due to dissolution of the organic phase, which is more pronounced in control group [51]. This is in accordance with previous reports, that the relative mineral loss of demineralizing lesion in the fluoride varnish group was $30 \%$ less than the control. The varnish was suggested to slow down the progress of demineralization but did not completely inhibit the enamel lesions. A high bacterial challenge cannot be completely overcome by fluoride varnish [52].

Finally, high surface irregularity, defective crystal arrangement and wide inter-crystalline spaces were reported in the current study in the control group, reflecting dissolution of crystals and the organic phase [51] in addition to demineralization of enamel in orthodontic patients without enamel protection.

\section{CONCLUSIONS}

Within the limitation of the study the following conclusions can be drawn:

- The use of varnish, unfilled sealant and Pro Seal in orthodontic patients with brackets resulted in a significantly lower mean roughness height and total surface area with no signs of surface demineralization or loss of surface details.

- There was no significant difference between the three groups (Varnish, unfilled sealant and Pro Seal) groups regarding roughness height, however, roughness surface area was lower in Pro Seal than those of Varnish and unfilled sealant groups.

- Pro Seal may be considered as an efficient preventive method in reducing enamel demineralization around orthodontic brackets.

\section{ACKNOWLEDGEMENT}

None declared.

\section{CONFLICT OF INTREST}

None declared.

\section{REFERENCES}

[1] Zimmer W.B., Rollwinkel Y. Assessing patient-specific decalcification risk in fixed orthodontic treatment and its impact on prophylactic procedures. Am J Orthod Dentofacial Orthop 2004; 126: 31824.

[2] Chadwick LB, Roy J, Knex J, Treasure TE. The effect of topical fluorides on decalcifications of patients with fixed orthodontic appliance: a systemic review: Am J Orthod Dentofacial Orthop 2005; 128: 301-6.

[3] Hu W, Featherstone JD. Prevention of enamel demineralization: an in-vitro study using light cured filled sealant. Am J Orthod Dentofacia Orthop 2005; 128: 592-600.

[4] Gorelick L, Geiger M, Gwinnet AJ. Incidence of white spot formation after bonding and banding. Am J Orthod 1982; 81: 93-8.
[5] Ögaared B. Prevalence of white spot lesions in 19 years old: a study on untreated and orthodontically treated persons 5 years after treatment. Am J Orthod Dentofacial Orthop 1989; 96: 423-7.

[6] Basdra EK, Huber H, Komposch G. Fluoride Release from orthodontic bonding agents alters enamel surface and inhibits enamel demineralization in vitro. Am J Orthod Dentofacial Orthop 1999; 11: 205- 14 .

[7] Schwaninger B, Vickers- Schwaninger N. Developing an effective oral hygiene program for the orthodontic patients: review rationale, and recommendations. Am J Orthod 1979; 75: 474-82.

[8] Ramaglia L, Sbordone L, Ciaglia RN, Barone A, Martina R. A clinical comparison of the efficacy and efficiency of two professional prophylaxis procedures in orthodontic patients. Eur J Orthod 1999; 21: 423-8.

[9] Anderson GB, Bowden J, Morrison EC, Caffesse RG. Clinical effects of chlorhexidine mouth washes on patients undergoing orthodontic treatment. Am J Orthod Dentofacial Orthop 1997; 111: 606-12.

[10] Zachrisson BU. Fluoride application procedures in orthodontic practice, current concepts. Angle Orthod 1975; 45: 72-81.

[11] O'Reilly MM. Featherstone JDB. Demineralization and remineralization around orthodontic appliances: an in vivo study. Am J Orthod Dentofacial Orthop 1987; 92: 33-40.

[12] Ten Cate JM. Current concepts on the theories of the mechanism of action of fluoride. Acta Odontol Scand 1999; 57: 325- 9.

[13] Ögaard B, Rolla G, Arends J. Orthodontic appliance and enamel demineralization. Part 1, lesion development. Am J Orthod Dentofacial Orthop 1988; 94: 68-73.

[14] Stratemann MW, Shannon IL. Control of decalcification in orthodontic patients by daily self-administered application of a waterfree $0.4 \%$ stannous fluoride gel. Am J Orthod 1974; 66: $273-9$.

[15] Ögaard B, Rolla G, Arends J, Ten Care JM. Orthodontic appliances and enamel demineralization. Part 2, prevention and treatment of lesions. Am J Orthod Dentofacial Orthop 1988; 94: 123- 8.

[16] Adriaens ML, Dermaut LR, Verbeeck MH. The use of "Fluor Protector" a fluoride varnish as a caries prevention method under orthodontic molar bands. Eur J Orthod 1990; 12: 316-9.

[17] Geiger AM, Gerolick L, Gwinnett AJ, Benson BJ. Reducing white spot lesions in orthodontic populations with fluoride rinsing. Am J Orthod Dentofacial Orthop 1992; 101: 403-7.

[18] Rezk-Lega F, Ögaard B. Tensile bond force of glass ionomer cement in direct bonding of orthodontic brackets: an in vitro comparative study. Am J Orthod Dentofacial Orthop 1991; 104: 47-52.

[19] Compton AM, Meyers CE, Hondrum So, Lorton L. Comparison of the shear bond strength of a light-cured glass ionomer and chemically cured glass ionomer for use as an orthodontic bonding agent. Am J Orthod Dentofacial Orthop 1992; 101: 138- 44.

[20] Mc Neil CJ, Wiltshire WA. Dawes C, Lavelle CL. Fluoride release from new light-cured orthodontic bonding agents. Am J Orthod Dentofacial Orthop 2001; 120: 392-7.

[21] Whealer AW, Foley TF, Mamandras A. Comparison of fluoride release protocols for in-vitro testing of 3 orthodontic adhesives. Am J Orthod Dentofacial Orthop 2002; 121: 301-9.

[22] Schmit JL, Staley RN, Wefel JS, Kanellis M, Jakobson JR, Keenan PJ. Effect of fluoride varnish on demineralization adjacent to brackects bonded with RMGI. Am J Orthod Dentofacial Orthop 2002; 122: 125-34.

[23] Gaworski M, Weinstein M, Borislow AJ, Braitman LE. Decalcification and bond failure: a comparison of glass ionomer cement or a resin adhesive. Angle Orthod 1999; 69: 65-70.

[24] Millett DT, Nunn JH, Welbury RR, Gordon PH. Decalcification in relation to brackets bonded with glass ionomer cement or a resin adhesive. Angle Orthod 1999; 116: 518-22.

[25] Gorton J, Featherstone JDB. In vivo inhibition of demineralization around orthodontic brackets. Am J Orthod Dentofacial Orthop 2003; 123:10-14.

[26] Pascotto RC, Navarro MF, Filho LC, Cury JA. In vivo effect of a resin modified glass ionomer cement on enamel demineralization around orthodontic brackets. Am J Orthod Dentofacial Orthop 2004; 125: 36-41.

[27] Zachrisson BU. Causes and prevention of injuries to teeth and supporting structures during orthodontic treatment. Am J Orthod 1976; 69: 285-300

[28] Tillery TJ, Hembree JH, Weber FN. Preventing enamel decalcification during orthodontic treatment. Am J Orthod 1976; 70: 435-9. 
[29] Zachrisson BU, Heimgard E. Ruyter IE, Mjor IA. Problems with sealants for bracket bonding. Am J Orthod 1979; 75: 64-9.

[30] Cee RF, Gwinnett AJ. Microscopic evaluation of the thickness of sealants used in orthodontic bonding. Am J Orthod 1980; 78: 6239.

[31] Joseph VP, Rossouw RE, Basson NJ. Some "Sealants" seal- a scanning electron microscopy (SEM) investigation. Am J Orthod Dentofacial Orthop 1994; 105: 362-8.

[32] Frazier MC, Sothard TE, Doster PM. Prevention of enamel demineralization during orthodontic treatment: an in vitro study using pit and fissure sealants. Am J Orthod Dentofacial Orthop 1996; 110: 459-65.

[33] Wenderoth CJ, Weinstein M, Borislow AJ. Effectiveness of a fluoride resin in reducing decalcification during orthodontic treatment. Am J Orthod Dentofacial Orthop 1999; 166: 629-34.

[34] Paschos E, Okuka S, Ilie N, Nuth KC, Hickel R,Rudzki-Janson I. Investigation of shear-peel bond strength of orthodontic brackets on enamel after using Pro seal. Am J Orthod Dentofacial Orthop 2006; 67: 196-206.

[35] Bishara SE, Oonsombat C, Soliman MM, Warren J. Effect of using a new protective sealant on the bond strength of orthodontic brackets. Angle Orthod 2005; 75: 243-6.

[36] Barbour ME, Parker DM, Allen GC, Jandt KD. Enamel dissolution in citric acid as a function of calcium and phosphate concentrations and degree of saturation with respect to hydroxyl apatite. Eur J Oral Sci 2003; 111: 428-33.

[37] Ikai A. STM and AFM of bio-organic molecules and structures. Surf Sci Rep .1996; 26: 263-332.

[38] Habelitz S, Maslall SJ, Marsall CW, Baloccch M. Mechanical properties of human dental enamel on the nanoscale. Arch Oral Biol 2001; 46: 173-83.

[39] Berkovitz BK, Holand GR, Maxham BJ. Oral anatomy, histology and embryology. $3^{\text {rd }}$ ed. Edinburgh, London, NY: Mosby inc. 2002; pp. 112-13.

[40] Farima M, Schemmel A, Weissmuller G, Cruz R, Kachar B, Bisch PM. Atomic force microscopy study of the tooth surfaces. J Struct Biol 1999; 125: 39-49.
[41] Schaad P, Paris E, cuisinier FJ, voegel JC. Atomic force microscopy study of human tooth enamel surface. Scann Microsc 1993; 4: $1149-52$

[42] Kirkham J, Zhang J, Brookers SJ, et al. Evidence for charge domains of developing Enamel crystal surfaces. J Dent Res 2000; 79: 1943-7.

[43] Fincham AG, Moradian-Oldak J, Simmer JP, et al. Self-assembly of a recombinant amelogenin protein generates supramolecular structures. J Struct Biol 1994; 112: 103-9.

[44] Robinson C, Fuchs P, Weatherell JA. The appearance of developing rat incisor using a freeze fracture technique. J Cryst Growth 1981; 53: 160-5.

[45] Cain K, Hick J, English J, Flaitz C, Powers JM, Rives T. In vitro enamel caries formation and orthodontic bonding agents. Am J Dent 2006; 19: 187-92

[46] Banks PA, Richmond S. Enamel sealants: a clinical evaluation of their value during fixed appliance therapy. Eur J Orthod 1994; 16 : 19-25.

[47] Wenderoth CJ, Weinslein J, Borislow AJ. Effectiveness of a fluoride- releasing sealant in reducing decalcification during orthodontic treatment. Am J Orthod Dentofacial Orthop 1999; 166: 629-34.

[48] Ceen RF, Gwinnett AJ. Microcopic evaluation of the thickness of sealants used in orthodontic bonding. Am J Orthod 1980; 78: 6239.

[49] Joseph VP, Rossouw PE, Basson NJ. Do sealant seal? An SEM investigation. J Clin Orthodont 1992; 26: 141-4.

[50] FraZier MC, Southward TE Dosler PM. Prevention of enamel demineralization during orthodontic treatment: an in vitro study using pit and fissure sealants. Am J Orthod Dentofacial Orthop 1996; 110: 459-65.

[51] Todd MA, Slaley RN, Kanellis MJ, Donly KJ, Wefel JS. Effect of fluoride varnish on demineralization adjacent to orthodontic brackets. Am J Orthod Dentofacial Orthop 1999; 116: 159-67.

[52] Gaballa SM, Ghobashy SA. Effect of fluoride varnish versus lightcured resin sealants on enamel demineralization in vivo. Egp Orthod J 2002; 22: 19-31.

Received: June 28, 2011

Revised: August 18, 2011

Accepted: August 19, 2011

(C) Shinaishin et al.; Licensee Bentham Open.

This is an open access article licensed under the terms of the Creative Commons Attribution Non-Commercial License (http://creativecommons.org/licenses/by-nc/3.0/) which permits unrestricted, non-commercial use, distribution and reproduction in any medium, provided the work is properly cited. 